This item was submitted to Loughborough's Research Repository by the author.

Items in Figshare are protected by copyright, with all rights reserved, unless otherwise indicated.

\title{
Drilling in cortical bone: a finite element model and experimental investigations
}

\section{PLEASE CITE THE PUBLISHED VERSION}

http://dx.doi.org/10.1016/j.jmbbm.2014.10.017

PUBLISHER

(C) Elsevier

VERSION

AM (Accepted Manuscript)

\section{PUBLISHER STATEMENT}

This work is made available according to the conditions of the Creative Commons Attribution-NonCommercialNoDerivatives 4.0 International (CC BY-NC-ND 4.0) licence. Full details of this licence are available at: https://creativecommons.org/licenses/by-nc-nd/4.0/

\section{LICENCE}

CC BY-NC-ND 4.0

\section{REPOSITORY RECORD}

Lughmani, Waqas, Kaddour Bouazza-Marouf, and lan A. Ashcroft. 2014. "Drilling in Cortical Bone: A Finite Element Model and Experimental Investigations". Loughborough University. https://hdl.handle.net/2134/16549. 


\title{
Drilling in cortical bone: A Finite element model and experimental investigations
}

\author{
Waqas A Lughmani ${ }^{a}$, Kaddour Bouazza-Marouf ${ }^{a}$, Ian Ashcroft ${ }^{b}$ \\ a Wolfson School of Mechanical and Manufacturing Engineering, Loughborough \\ University, LE11 3TU, Leics, UK \\ ${ }^{\mathrm{b}}$ Department of Mechanical, Material and Manufacturing Engineering, The University \\ of Nottingham, NG7 2RD, Nottingham, UK
}

Corresponding Author: Waqas A Lughmani , email: W.A.Lughmani@lboro.ac.uk

Telephone: $+44(0) 1509227566$

\begin{abstract}
Bone drilling is an essential part of many orthopaedic surgery procedures, including those for internal fixation and for attaching prosthetics. Estimation and control of bone drilling forces are critical to prevent drill-bit breakthrough, excessive heat generation, and mechanical damage to the bone. An experimental and computational study of drilling in cortical bone has been conducted. A 3D finite element (FE) model for prediction of thrust forces experienced during bone drilling has been developed. The model incorporates the dynamic characteristics involved in the process along with geometrical considerations. An elastic-plastic material model is used to predict the behaviour of cortical bone during drilling. The average critical thrust forces and torques obtained using FE analysis are found to be in good agreement with the experimental results.
\end{abstract}

Keywords: Bone drilling, Orthopaedic surgery, Finite element, Experimental testing, Yield surface 


\section{Introduction}

In orthopaedics surgery, drilling and tapping are extensively carried out before the insertion of screws. The desired outcome of bone drilling is to drill holes of the required diameter without mechanical and thermal damage to the bone and without affecting the surrounding tissues.

At present, in orthopedic surgery, bone drilling is performed using hand drills and the feed rate of the drill-bit is manually controlled by the surgeon. The drilling performance depends, on a great extent, on the surgeon's manual skill and 'drilling by feeling' (G. Augustin et al. 2012). The drilling force sensed by the surgeon is subjective; it depends on the feed rate of the drill-bit, the quality of the bone and the type of drill-bit used. Drilling into bone is a fundamental skill that can be both very simple, such as drilling through long bones, or very difficult, such as drilling through the vertebral pedicles where incorrectly drilled holes can result in nerve damage, vascular damage or fractured pedicles (Van Brussel et al. 1996, Carmouche et al. 2005). Large forces experienced during bone drilling may result in drill overrun, causing considerable damage to surrounding tissues (Ong et al. 1999, Brett et al. 2004) and may promote crack formation (Kasiri et al. 2010). Similarly, drilling forces are the major contributor to heat generation during bone drilling (Augustin et al. 2008), which can cause thermal necrosis (Eriksson et al. 1984, Bachus et al. 2000, Davidson et al. 2003). Previous studies (Farnworth et al. 1974, Bassi et al. 2008, Price et al. 2002) have shown that uncontrolled drilling forces and torques could cause surgical complications due to the drill-bit breakage. It is also important in manual bone drilling to learn to anticipate drill-bit breakthrough and the necessary change in force depending on the quality and density of the bone, which is anisotropic and living. Diseases such as osteoporosis and cancer affect the quality and density of the bone, and thus affect the drilling thrust force. It is therefore important to understand the effects of bone drilling conditions, drill-bit geometry and material behaviour on the bone drilling forces to select favourable drilling conditions, and assist in robotic assisted surgical procedures (Ong et al. 1998, 1999, 2000, HSU 2001).

Experimental, analytical and numerical modeling techniques have been used by many researchers to study the drilling mechanism in bone. Experimental studies 
examined the effects of spindle speed (Thompson 1958, Jacob et al. 1976, Hobkirk et al. 1977) and feed rate (Jacob et al. 1976, Wiggins et al. 1976) on the thrust force and torque experienced during bone drilling. It was seen that increased drill-bit rotational speed results in lower drilling force, and higher feed rate produce higher thrust force and torque. Similarly, the effect of drill-bit geometry on bone drilling forces has been investigated experimentally (Farnworth et al. 1974, Jacob et al. 1976, Hobkirk et al. 1977, Karmani et al. 2004, Saha et al. 1982), and twist drill-bits with lower point angle and large helix angle were seen to produce lower forces but were also seen to cause drill-bit breaking.

In analytical studies, drilling models developed for metals have been applied to bone drilling to estimate the bone drilling forces, and in order to apply machining theory of metals to bone, an assumption was made that bone behaves like metal when it is machined (Wiggins et al. 1976, Allotta et al. 1996, Lee et al. 2012). The results obtained by Wiggin et al. (1976) did not show a good correlation between theoretical and experimental drilling force data. Allotta et al. (1996) ignored the effect of chisel edge and their estimated specific cutting energy is not supported in the literature. Karalis et al. (1982) applied the theory of rock mechanics in bone drilling. However, the coefficient of determination found was very low $\left(r^{2}=0.23\right)$, so the validity of the formulation is not entirely convincing. More recently, an enhanced model of drilling forces during bone drilling was derived (Lee et al. 2012). However, all the mechanistic models used empirical equations to calculate cutting parameters, and the specific cutting energy, obtained from a number of calibration tests, is only valid for a certain range of cutting conditions and drill-bit geometries.

Only a few numerical studies in the literature have attempted to model bone drilling and the cutting process. A Finite element (FE) model was used by Tu et al. (2008) to simulate the rise of temperature in bone during drilling. However, the model did not consider force calculations and was not validated experimentally. Childs et al. (2011) have applied a metal machining FE model, including a strain accumulation damage law to predict chip formation and forces in bone machining. It was concluded that the material model is the primary factor contributing to the simulated specific cutting force. The literature also showed that the mechanical characteristics of bone during drilling depend upon the amount of strain, strain rate and temperature (Hansen et al. 2008, Crowninshield et al. 1974, Pope et al. 1974). Therefore, the 
mechanics of bone drilling directly depends upon the drilling conditions, drill-bit geometry and material model of the bone.

The tremendous advancements in computing power in the last two decades have made the finite-element method very attractive in the modeling of metals and polymers machining process. Three kinds of mechanical formulation can be used to model machining in FE analysis. Strenkowski et al. (2004) used Eulerian FE, in which the grid is not attached to the material; this is computationally efficient but needs a continuous update of the free chip geometry. Leopold et al. (1999) used Lagrangian formulation, in which the grid is attached to the material; this method requires an update of the mesh (remeshing algorithm) or the use of an element removal criterion to form the chip from the workpiece (Ceretti et al. 1996). An alternative method is to use Arbitrary Lagrangian Eulerian (ALE) formulation (Pantale et al. 1996) in which the grid, which is not attached to the material, moves to avoid distortion and the free chip geometry needs updating continuously (i.e. continuous remeshing). Chen (1997) applied FE to design drill-bits based on drill-bit deformation. Pantale (2004) developed 2D and 3D FE cutting models with damage effects for metals. These models were able to predict the formation of chips and the cutting forces during the process depending on the material machined. All of these studies have proven that FE modeling is effective in predicting cutting forces under varying cutting conditions and cutting tools.

In this work, we have used the Lagrangian formulation with the element removal scheme to simulate drilling. We present a FE model for the bone drilling process to enable prediction of bone drilling forces as a function of drilling conditions, drill-bit geometry and material model of bone. In this model, dynamic effect, constitutive damage law and contact friction are taken into account. The yield stress is taken as a function of strain and strain rate. The damage constitutive law adopted here allows advanced simulations of tool penetration and material removal. The model is then experimentally evaluated using cortical portions of bovine femur.

\section{FE model of drilling}

Considering the similarity in the mechanics of bone drilling to that of metal and polymers, FE methods can provide a framework to develop a numerical model, which could reasonably predict the levels of thrust force and torque within a relatively reasonable computational time. In this work, a three dimensional (3D) Lagrangian FE 
model of drilling in cortical bone has been developed using a commercially available FE software ABAQUS/Explicit. The behaviour of cortical bone in elastic regime was defined using the Hill's potential theory for anisotropic materials (Hill 1952, 1990) together with the rate dependent plasticity criterion. An element removal scheme was used based on ductile damage initiation criterion to replicate the hole making process.

\subsection{Constitutive material model}

Bone as an anisotropic material exhibits different yield behaviour in different directions. The present work is based on the modeling of anisotropic yield behaviour of cortical bone using yield stress ratios. In this study bone material is considered as a transversely isotropic material with five independent elastic constants. The long axis of the bone has been taken as the axis of symmetry. The transversely isotropic model proposed in this work is based on the Hill's quadratic yield criterion for anisotropic material (Hill 1952, 1990) and a non-linear isotropic hardening rule for rate dependent plasticity. The constitutive equations of this model for uniaxial loading are as follows:

The total strain tensor during deformation is the sum of elastic strain tensor and plastic strain tensor, given by,

$\varepsilon=\varepsilon^{e l}+\varepsilon^{p l}$

In this case the yield ratios were defined with respect to a reference yield stress, $\sigma^{\circ}$ (a user-defined reference yield stress specified for the material plasticity). For anisotropic yielding Hill's potential function can be expressed in terms of rectangular stress components as given by,

$$
\begin{aligned}
f(\sigma)= & \left(F\left(\bar{\sigma}_{22}-\bar{\sigma}_{33)}\right)^{2}+G\left(\bar{\sigma}_{33}-\bar{\sigma}_{11}\right)^{2}+H\left(\bar{\sigma}_{11}-\bar{\sigma}_{22}\right)^{2}+2 L \bar{\sigma}_{23}{ }^{2}+2 M \bar{\sigma}_{31}{ }^{2}+\right. \\
& \left.2 N \bar{\sigma}_{12}\right)^{1 / 2} \\
f(\sigma)= & \left|\sigma^{y}\right|+R
\end{aligned}
$$

where $\mathrm{F}, \mathrm{G}, \mathrm{H}, \mathrm{L}, \mathrm{M}$ and $\mathrm{N}$ are constants, obtained from the following equations, $F=\frac{1}{2}\left(\frac{1}{R_{33}^{2}}+\frac{1}{R_{22}^{2}}-\frac{1}{R_{11}^{2}}\right)$, 


$$
\begin{aligned}
& G=\frac{1}{2}\left(\frac{1}{R_{33}^{2}}+\frac{1}{R_{11}^{2}}-\frac{1}{R_{22}^{2}}\right), \\
& H=\frac{1}{2}\left(\frac{1}{R_{11}^{2}}+\frac{1}{R_{22}^{2}}-\frac{1}{R_{33}^{2}}\right), \\
& L=\left(\frac{3}{2 R_{23}^{2}}\right), \\
& M=\left(\frac{3}{2 R_{13}^{2}}\right), \\
& N=\left(\frac{3}{2 R_{12}^{2}}\right) .
\end{aligned}
$$

Here $\bar{\sigma}$ is the measured yield stress when applied as the only non-zero stress component, $\mathrm{R}_{i j}$ are anisotropic yield ratios and can be calculated from the cortical bone yield strengths. $\sigma^{y}$ is the size of an initial yield surface.

$R$ is the isotropic hardening term given as:

$R=\sigma^{0}\left(\varepsilon^{p l}, \theta^{0}\right)$

Here $\theta^{0}$ is the temperature of the cortical bone. For 2-3 plane to be the plane of isotropy at every point, transverse isotropy requires that $E_{1}=E_{p}, E_{2}=E_{3}=E_{t}, v_{12}=$ $\nu_{13}=v_{p t}, \nu_{21}=v_{31}=v_{t p}$ and $G_{12}=G_{13}=G_{t}$ where $p$ and $t$ stand for in-plane and transverse respectively.

The rate-dependent properties of the cortical bone were also defined using the Cowper-Symonds overstress power law (Cowper et al. 1957):

$$
\dot{\bar{\varepsilon}}^{p l}=d\left(\frac{\sigma}{\sigma_{0}}-1\right)^{n}
$$

where $\sigma$ is the yield stress under different strain rates, $\sigma_{0}$ is the static strain rate, and $d$ and $n$ are material constants. 


\subsection{Element removal scheme}

Here, simulation of the hole-generation process in cortical bone was accomplished with the help of the element removal scheme in Abaqus/Explicit. The chip formation was not modelled, and the damage initiation in the cortical bone was based on a ductile damage criterion. The ductile criterion is specified by providing the equivalent plastic strain at the onset of damage, $\bar{\varepsilon}_{D}^{p l}$, which is a function of stress triaxiality and strain rate:

$\bar{\varepsilon}_{D}^{p l}\left(\eta, \dot{\bar{\varepsilon}}^{p l}\right)$

where $\eta=p / q$ is the stress triaxiality ( $p$ is the pressure stress and $q$ is the Mises equivalent stress). The criterion for damage initiation is met when the following condition is satisfied by $\omega_{\mathrm{D}}$, a state variable that increases monotonically with plastic deformation, and is proportional to the incremental variation in the equivalent plastic strain. :

$$
\omega_{D}=\int\left(\frac{1}{\bar{\varepsilon}_{D}^{p l}\left(\eta, \dot{\bar{\varepsilon}}^{p l}\right.}\right) d\left(\bar{\varepsilon}^{p l}\right)=1
$$

The characteristic stress-strain behaviour of a material under uni-axial loading that undergoes progressive damage is shown in Fig. 1.

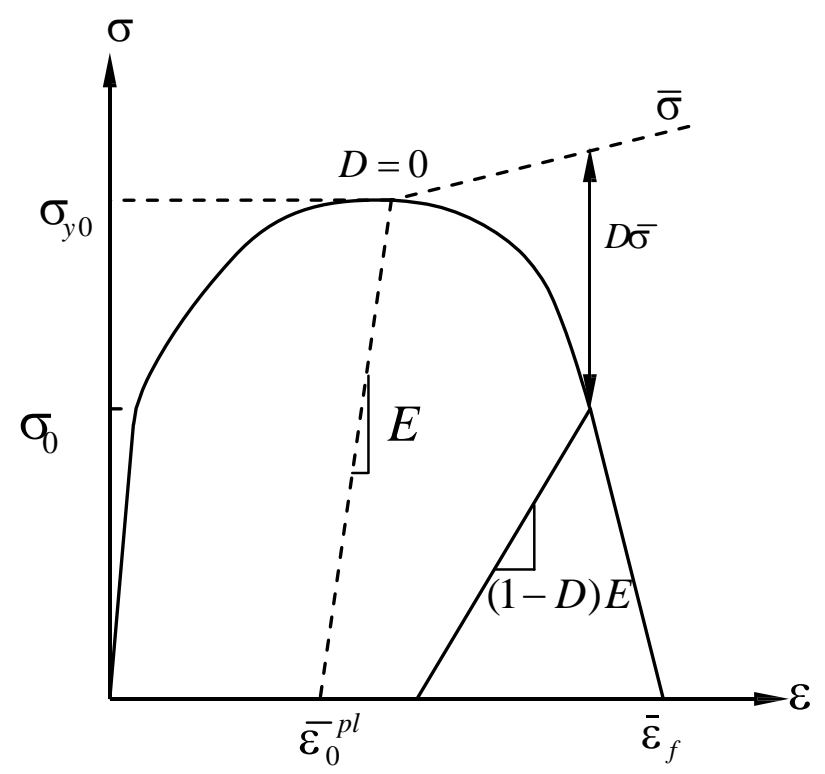

Fig. 1. Stress-strain curve with damage behaviour 
In the case of the elastic-plastic material, this damage can be decomposed into two parts; softening of the yield stress and degradation of the elastic modulus. The solid curve in Fig. 1 represents the damaged stress-strain response, whereas the dashed line represents the undamaged behaviour. $\sigma_{\mathrm{yo}}$ and $\bar{\varepsilon}_{0}^{p l}$ are yield stress and equivalent plastic strain at the onset of damage respectively, while $\bar{\varepsilon}_{f}$ is the equivalent plastic strain at failure, also known as fracture strain. $D$ is the overall damage parameter: with $D=0$ at damage initiation, and $D=1$ at complete damage. After damage initiation, the residual elastic modulus, $E_{r}$, is given as:

$E_{r}=(1-D) \cdot E$

When the material undergoes damage, the stress-strain relationship fails to accurately represent its behaviour because of a strong mesh dependency linked to the strain localisation. Hence, a different approach is required to trace the strain softening branch of the stress-strain curve. Thus, Hillerborg's fracture energy approach (Hillerborg 1985) was employed in this model, which helped to reduce mesh dependency by formulating a stress displacement response after damage initiation. The fracture energy was idealised as work required to open a unit area of a crack; it is expressed as:

$G_{f}=\int_{\bar{\varepsilon} p l}^{\bar{\varepsilon}_{f}^{p l}} l \sigma_{y} d \bar{\varepsilon}^{p l}=\int_{0}^{\bar{u}_{f}^{p l}} \sigma_{y} d \bar{u}^{p l}$

where $\bar{u}^{p l}$ is the equivalent plastic displacement and can be considered as fracture energy conjugate of yield stress after the damage initiation: $\bar{u}^{p l}=0$ at damage initiation and $\bar{u}^{p l}=l \bar{\varepsilon}^{p l}$ after it. $l$ is the characteristic length of an element in a meshed body that depends on its geometry and formulation.

\subsection{Material properties}

As the cortical bone was modelled as transversely isotropic elasto-plastic rate dependent material, the quasi static properties were taken from the literature (Reilly et al. 1975). For rate dependent properties, split-Hopkinson pressure bar (SHPB) 
tests were conducted and a best-fit curve and constitutive constants for equation 5 were generated. The stress-strain curve of a material at a known strain rate could be scaled to determine the material properties at an unknown strain rate by using equation 5 with the respective material coefficients ( $d$ and $n$ ). The material properties of cortical bone used in the FE analysis are listed in Tables 1 and 2 below.

\section{Table 1.}

Mechanical parameters of cortical bone.

\begin{tabular}{lc}
\hline Property & Value \\
\hline Longitudinal stiffness, $\mathrm{E}_{11}(\mathrm{GPa})$ & 20 \\
Transverse stiffness, $\mathrm{E}_{22}(\mathrm{GPa})$ & 18 \\
Poisson's ratio, $\mathrm{v}_{12}$ & 0.34 \\
Poisson's ratio, $\mathrm{v}_{23}$ & 0.4 \\
Shear modulus, $\mathrm{G}_{12}(\mathrm{GPa})$ & 5 \\
Density (kg/m ${ }^{3}$ ) & 2000 \\
Materials constants $(\mathrm{d} / \mathrm{n})$ & $9897 / 0.65$ \\
\hline
\end{tabular}

\section{Table 2.}

Values of Rij for calculating Hill's potential constants.

\begin{tabular}{cccccc}
\hline R11 & R22 & R33 & R12 & R13 & R23 \\
\hline 1.2 & 1 & 1 & 0.77 & 0.77 & 0.88 \\
\hline
\end{tabular}

\subsection{Geometric modeling and boundary conditions}

A 3D FE model of drilling was developed which consists of a HSS twist drill-bit and cortical bone with appropriate boundary conditions as shown in Fig. 2a. A 3D geometry of a $2.5 \mathrm{~mm}$ diameter twist drill-bit with a point angle of $118^{\circ}$ and a helix angle of $28^{\circ}$ was modelled in Abaqus. The drill-bit was modelled as a rigid body because the elastic stiffness of the HSS twist drill-bit used is in the range of 220$240 \mathrm{GPa}$ as compared to $20 \mathrm{GPa}$ for the cortical bone; this reduces the computational cost involved in the highly resource-consuming drilling simulations. An elastic 
modulus of 235GPa was used for the drill-bit in this simulation. The mesh size of cortical bone was refined in the immediate vicinity of the drilled area to capture high stress gradients during the drilling process. The elements in the refined cylindrical zone were removed when the failure criterion was met during simulations using element deletion discussed in Section 2.2. The cortical bone was fixed at all four vertical faces, while the drill-bit was constrained to rotate only about its own longitudinal axis with a specified speed and fed vertically downwards into the work piece as shown in Fig. 2b. The FE analysis was performed with the drilling parameters listed in Table 3.

In this study, eight-node, first-order, one integration point hexahedral elements of type C3D8R were used. As the mesh-sensitivity study is very important in simulations involving high deformations and a non-linear material behaviour, a rigorous mesh-sensitivity study was carried out to obtain a computationally accurate finite-element mesh. In the current model, due to the implementation of the drill-bit and removal of material, the history of the force-time signal is used as the criterion of convergence. All the results are presented based on simulations performed with an optimised mesh. The computational time was reduced by introducing different mesh sizes in distinct regions of the FE model. The cortical bone was meshed with 101320 elements with a smallest element size of $5 \mu \mathrm{m}$. The drill-bit was modelled with fournode, 3D discrete rigid elements of type C3D4 and meshed with 4850 elements. Localised stiffness reduction due to internal damage can cause excessive element distortion that could lead to difficulties in numerical convergence. To resolve this numerical issue, 'distortion control' was used in Abaqus, and damage variables were limited to a maximum value of 0.999 . Following a wave stability study it was observed that the smallest element which governs the stability of the solution has a very low stable time increment of the order of $10^{-8} \mathrm{~s}$. This affected the overall solution run time, and hence a selective variable mass scaling technique was used for the element set in the refined cylindrical zone. The mass scaling increased the mass of the selected elements to $0.5 \%$ with a stable time increment of the order $10^{-7} \mathrm{~s}$. This had minimal effect on the kinetic energy of the model.

The contact and friction parameters used in the simulations were based on a number of experimental factors such as spindle speed, feed rate and drill-bit geometry. Contact between the twist drill-bit and cortical bone was defined by the general contact algorithm available in Abaqus/explicit. This algorithm generated the 
contact forces based on the penalty-enforced contact method. The friction coefficient $\mu$ is used to account for the shear stress of the surface traction, $T=\mu p$, (where $p$ is the contact pressure). In this case, the frictional contact between the drill-bit and cortical bone was modelled with a constant coefficient of friction of 0.7 (Davidson et al. 2003). The models required on average 54 hours on 36 Intel quad-core processors with 48 GB RAM each. A High Performance Computing (HPC) facility available at Loughborough University was used.

\section{Table 3.}

Machining parameters used in cortical bone drilling

\begin{tabular}{ll}
\hline Drill-bit & HSS, $\phi 2.5 \mathrm{~mm}$, point angle $118^{\circ}$ \\
Spindle speed (rpm) & $800,1200,1500$ \\
Feed (mm/rev) & $0.05,0.1,0.15,0.1875$ \\
\hline
\end{tabular}

(a)

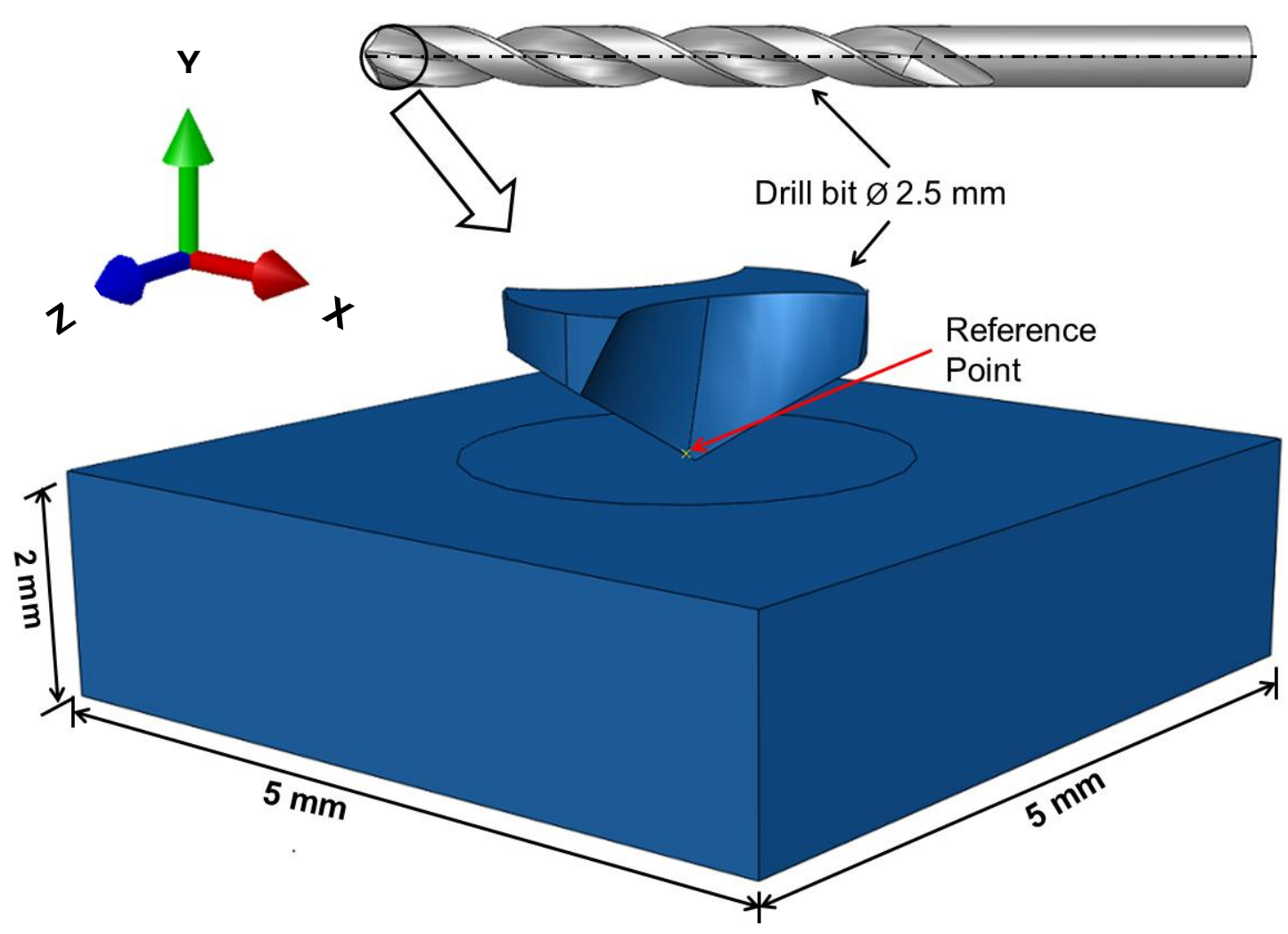


(b)

Boundary Conditions

- All Vertical faces of bone specimen are fixed

- Drill bit moves in $Y$ direction and rotates about $Y$ Axis

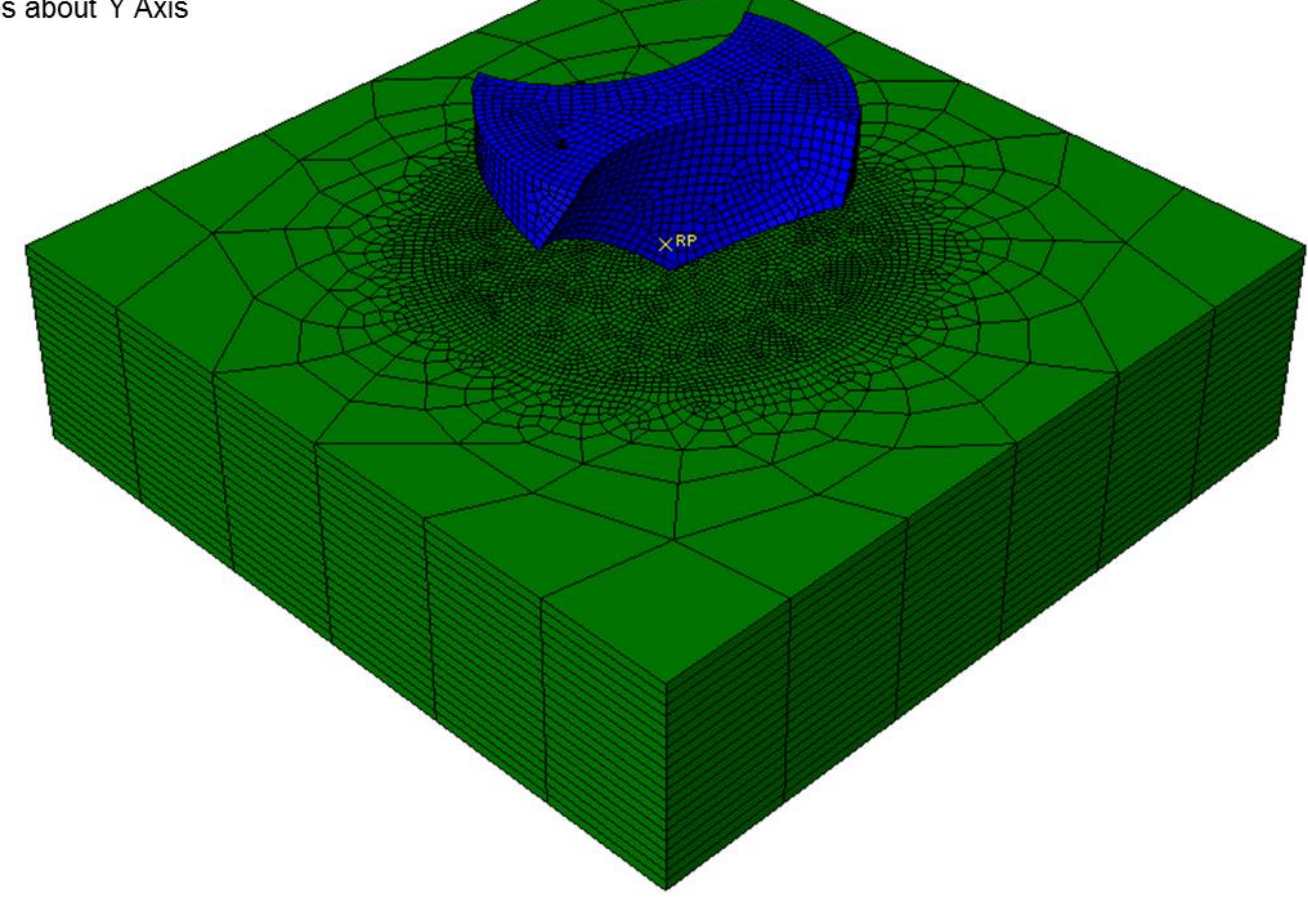

Fig. 2. (a) Finite element model of bone drilling (b) Meshing and boundary conditions

\section{Drilling Experiments}

\subsection{Specimen preparation}

Bovine bone was used in this research as it replicated the properties of human bone (Vashishth 2004). The bones were obtained from a local butcher and were stored frozen at $-10{ }^{\circ} \mathrm{C}$ before the tests. The bone used in the experiments was allowed to thaw for 24 hours just before the tests were carried out. The epiphysis was then cut off. The tests were carried out on the diaphysis of the femur bone, which is predominantly cortical bone. The bone pieces were $75-90 \mathrm{~mm}$ in length with an average thickness of the cortical wall of 7-9 $\mathrm{mm}$. However, the shape of the bone was not suitable for gripping the bone in a holding device. To eliminate this problem, the bone was cut into three parts along its longitudinal axis. One part of the bone (specimen) was screwed to the surface of a metal block, with the bone's top surface facing the drill-bit. A total of eight test specimens were prepared from the 
bone pieces, and every specimen was divided into seven equal sections, each accommodating approx. four drilled holes. The main stages of specimen preparation are shown in Fig. 3.

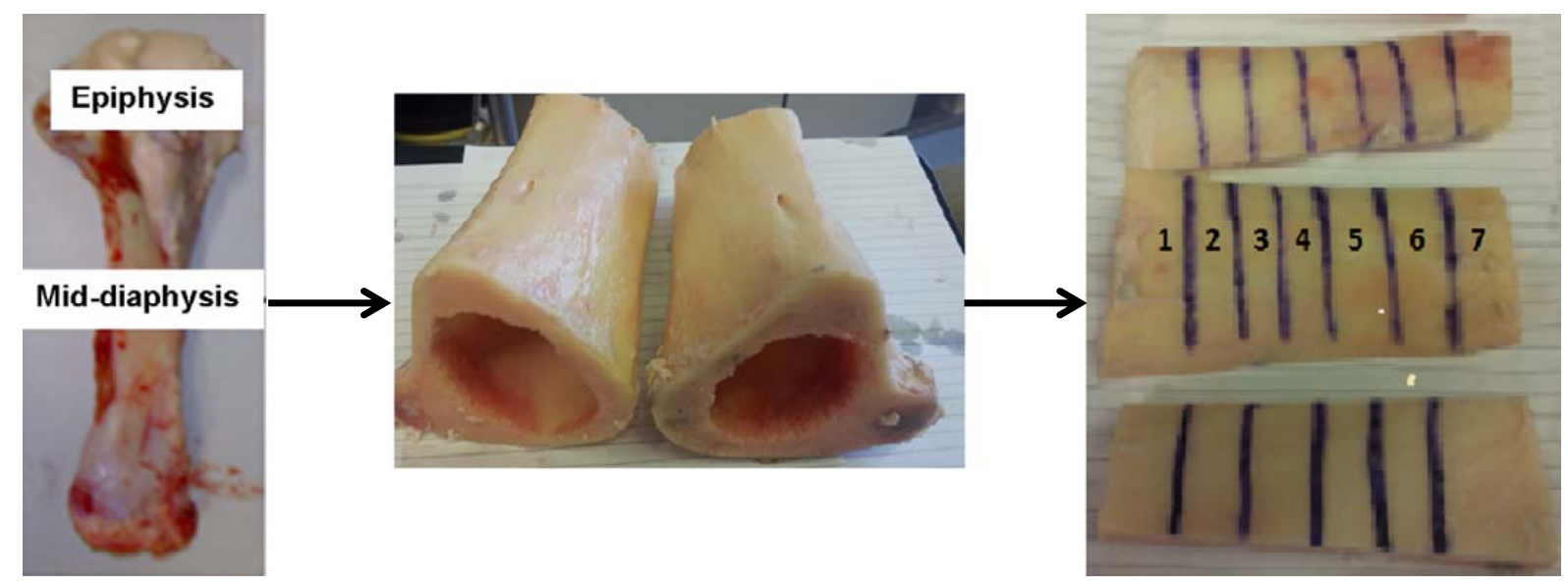

Fig. 3. Preparation of drilling specimen

\subsection{Experimental setup}

An electromechanical test rig, shown in Fig. 4a, was designed to carry out the drilling experiments. Test specimens were mounted on a force transducer (model no. LCM101-10, Omega Engineering Ltd., UK) which measured the drilling force during the drilling experiments. The force transducer was further mounted on a rotary table supported on ball bearings. The mounting arrangement is shown in Fig. 4b. The rotary movement of the rotary table is restricted using a strain gauged (Wheatstone bridge) cantilever beam; thus giving a measure of the drilling torque. Drill-bit guide bushings were used to guide the drill-bit and ensure that it is driven into the specimen at a $90^{\circ}$ angle. The drilling force was recorded at a sampling rate of 1000 $\mathrm{Hz}$. A 12-bit, eight channel data acquisition system was used for the data acquisition (model no. USB-1208FS, Measurement Computing Corp. UK). A constant drill feed rate was provided by a ball screw feed mechanism which was powered by a stepper motor. An encoder was mounted on the ball screw to directly record its rotation, which is converted into drill-bit displacement and feed rate using the lead measurement of the ball screw. During the drilling operation, the drill-bit feed rate was recorded via RS232 interface and displayed on the computer screen. This information was used to set the feed rate value and also to monitor any change in 
the feed rate during the drilling operation. The drilling was carried out at feed rates between $40 \mathrm{~mm} / \mathrm{min}$ and $282 \mathrm{~mm} / \mathrm{min}$, based on the assumption made about the approximate drilling time that a surgeon would take to perform drilling in clinics. The required drilling speed was provided by a DC servo motor with speed control. Drilling in the cortical bone specimens were carried out at drilling speeds of $800 \mathrm{rpm}$, $1200 \mathrm{rpm}$ and $1500 \mathrm{rpm}$, using diameter $2.5 \mathrm{~mm}$ industrial drill-bits (Model A9762.2X95 Dormer UK). This speed range was chosen to reduce the generation of high temperature during drilling. All the experiments were performed at room temperature without cooling as in real orthopaedic surgery. The minimum number of holes to be drilled into each section of cortical bone specimen, for the study to be $95 \%$ statistically significant, was calculated using the sample size calculation equation presented by (Dell et al.2002). A sample size of three was obtained. This was based on the calculated drilling force standard deviation value of $0.5 \mathrm{~N}$ and a margin of error of $0.65 \mathrm{~N}$ for the experimental setup using a homogenous material.

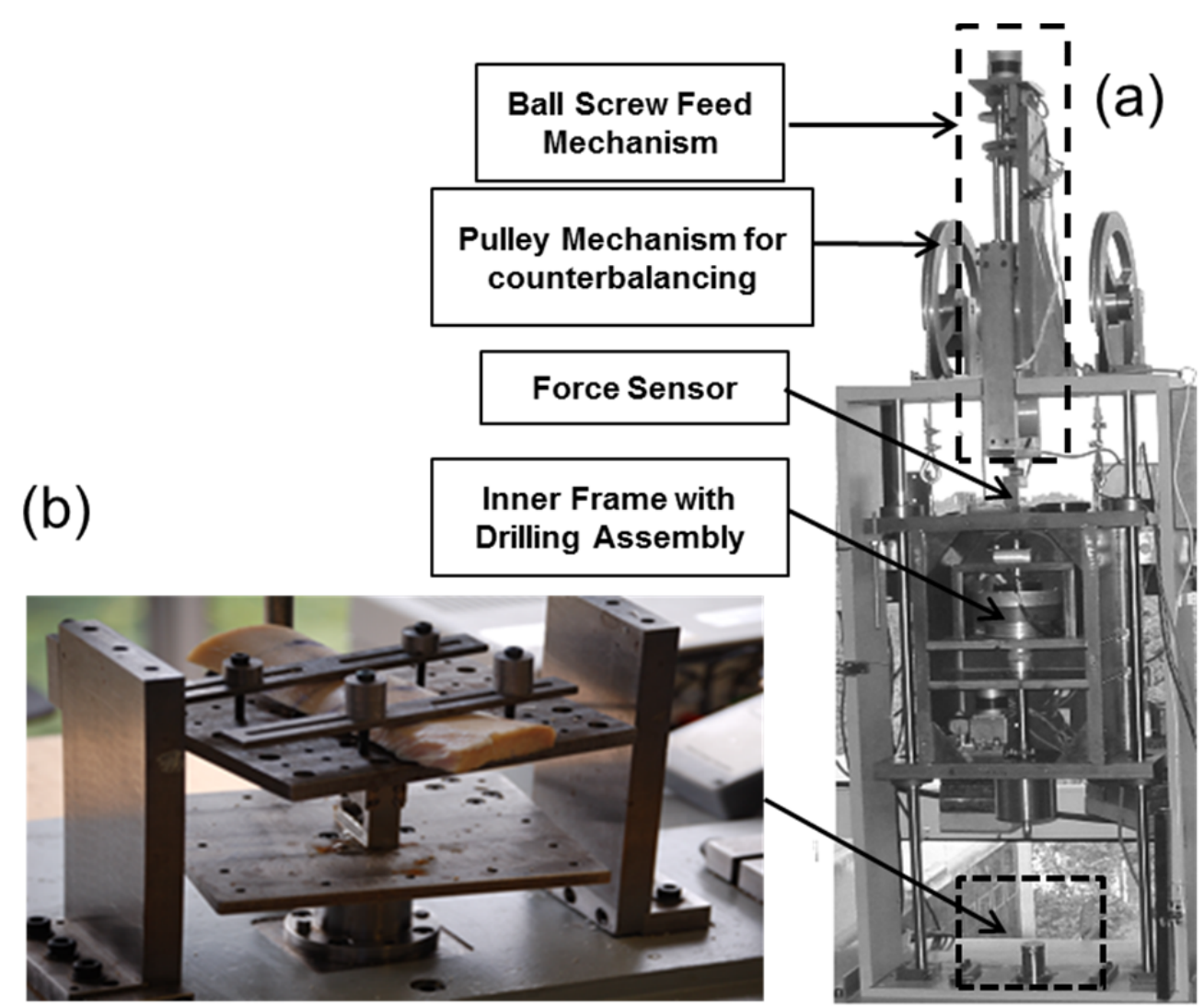

Fig. 4. (a) Drilling Test Rig (b) Mounting of Specimen 


\section{Results and discussion}

\subsection{FE Results}

To identify the maximum force and maximum torque easily, any noise in the force and torque data was filtered using the running average function. A typical profile of the drilling force with respect to drill-bit displacement for a single hole was obtained as shown in Fig. 5a. The drilling profile is divided into four zones. Zone I shows the penetration of the drill-bit, which can be seen by a sharp rise in the drilling force. Zone II shows the start of material removal by the chisel edge and main cutting edge with gradual rise in thrust force upon drill-bit entry into the anterior cortex. The Drill bit is fully engaged at the end of zone II and throughout zone III, and the maximum drilling force is calculated in zone III, Zone IV shows a gradual drop in thrust force as the drill-bit exits the cortex. Similar drilling force profiles having different drilling force magnitudes were observed for all the drilling conditions considered in this study. A typical torque profile is shown in Fig. 5b. It shows the same increasing trend as the thrust force upon drill-bit penetration.

The noise observed in the simulation results is due to the continuous makeand-break of contact between the drill-bit and bone upon removal of material. Such inherent noise caused by the "Alternating in and out" of drill-bit is due to the removal of material and the small stable time increment in the "explicit solver" used. The noise could be reduced through inducing artificial damping, but this will reduce the stable time further which results in high computational costs. 
(a)

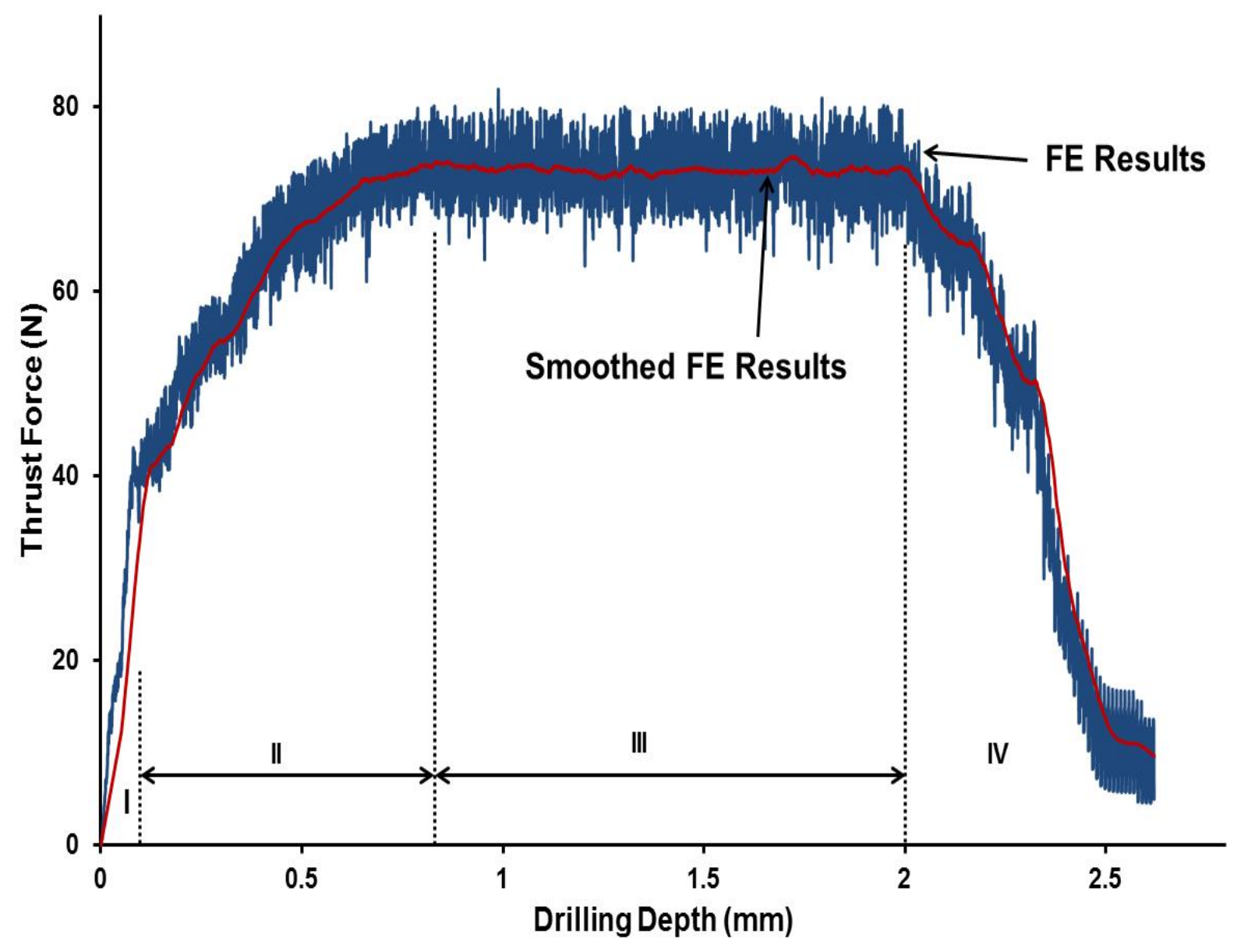


(b)

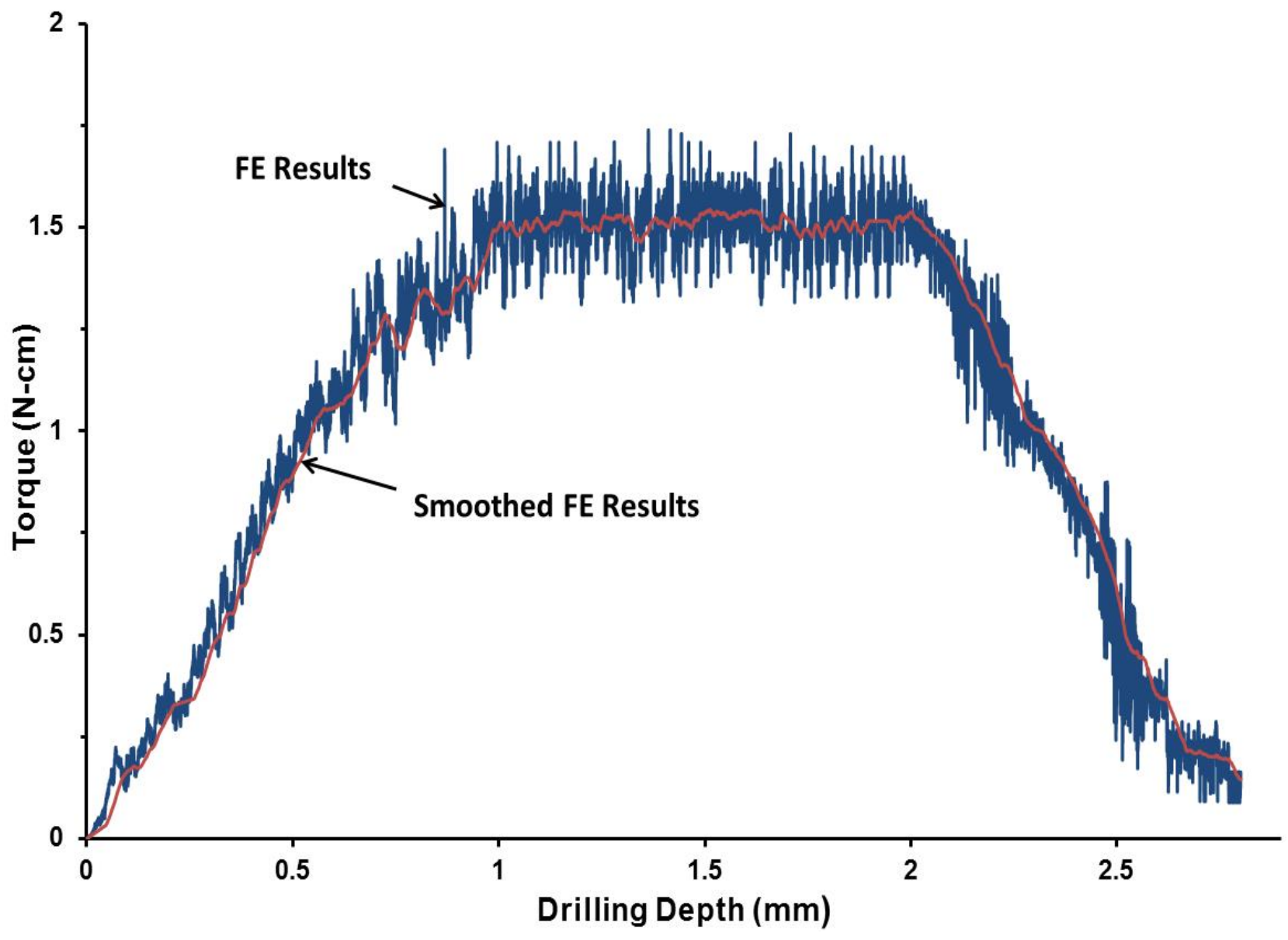

Fig. 5. FE Results at $150 \mathrm{~mm} / \mathrm{min}$ and $800 \mathrm{rpm}$ (Smoothed using the moving average function) (a) Thrust Force (b) Torque

\subsection{FE Model validation}

In order to allow a better comparison of the experimental and simulated drilling thrust force and torque, a feed rate of $150 \mathrm{~mm} / \mathrm{min}$ was chosen with a spindle speed of $800 \mathrm{rpm}$. This gives a feed rate with respect to the rotational speed of $0.1875 \mathrm{~mm} / \mathrm{rev}$. The FE simulations were carried out using these process parameters, which were subsequently used to predict the thrust force and torque for other feed rates. Figures $6 \mathrm{a}$ and $6 \mathrm{~b}$ show the experimental and simulation results of the drilling thrust force and torque in cortical bone. The noise in the simulated FE force and torque data has been filtered using the running average function. The average maximum thrust force (obtained for the period of complete drill engagement) in the experimental trials was between 70 and $75 \mathrm{~N}$, compared to $73 \mathrm{~N}$ for the $\mathrm{FE}$ simulated 
model. The experimentally measured torque was $1.54-1.62 \mathrm{Ncm}$ compared to an estimated torque of $1.5 \mathrm{Ncm}$ obtained from FE simulation. This shows that the FE model estimated the thrust force and torque accurately.

(a)

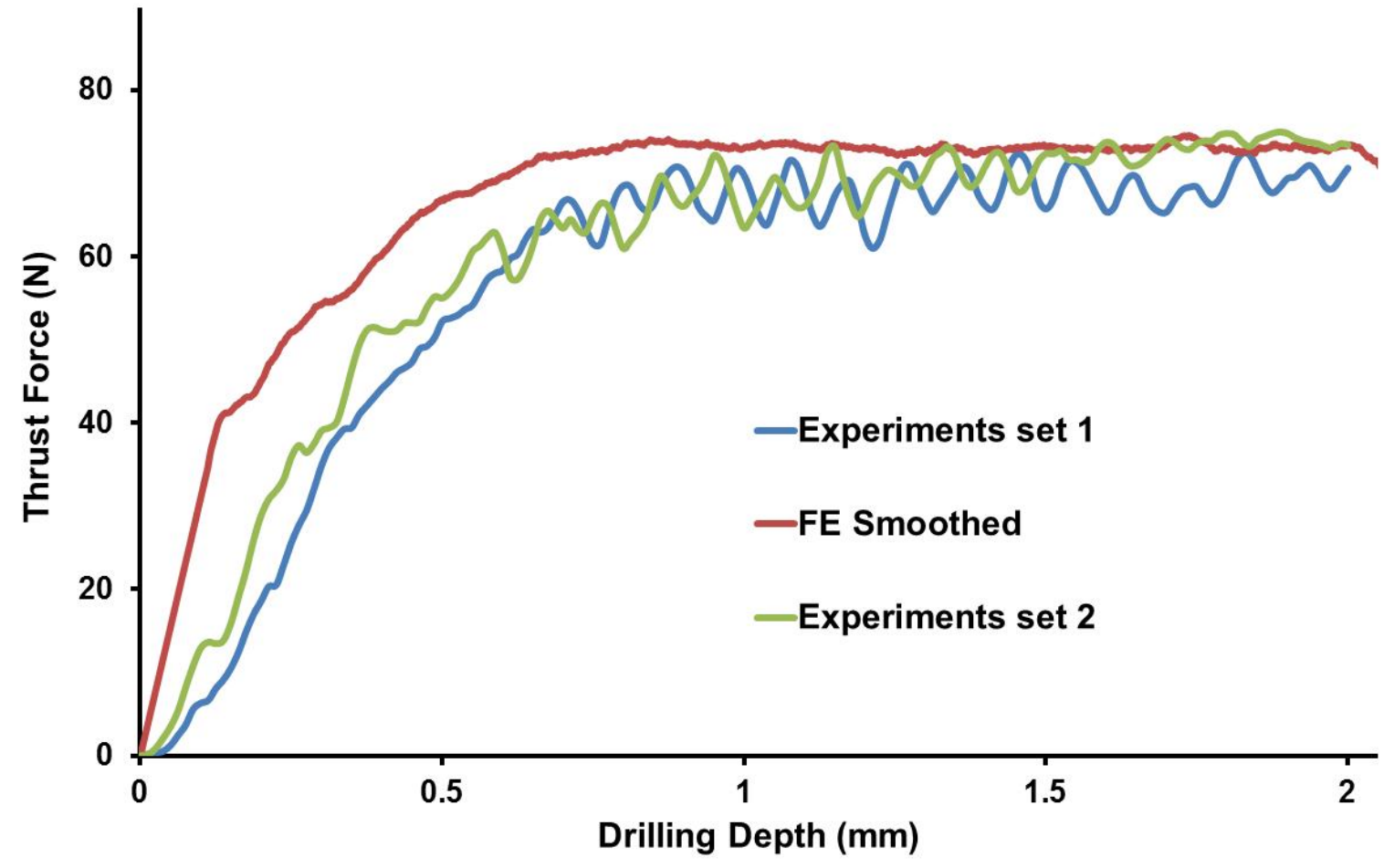


(b)

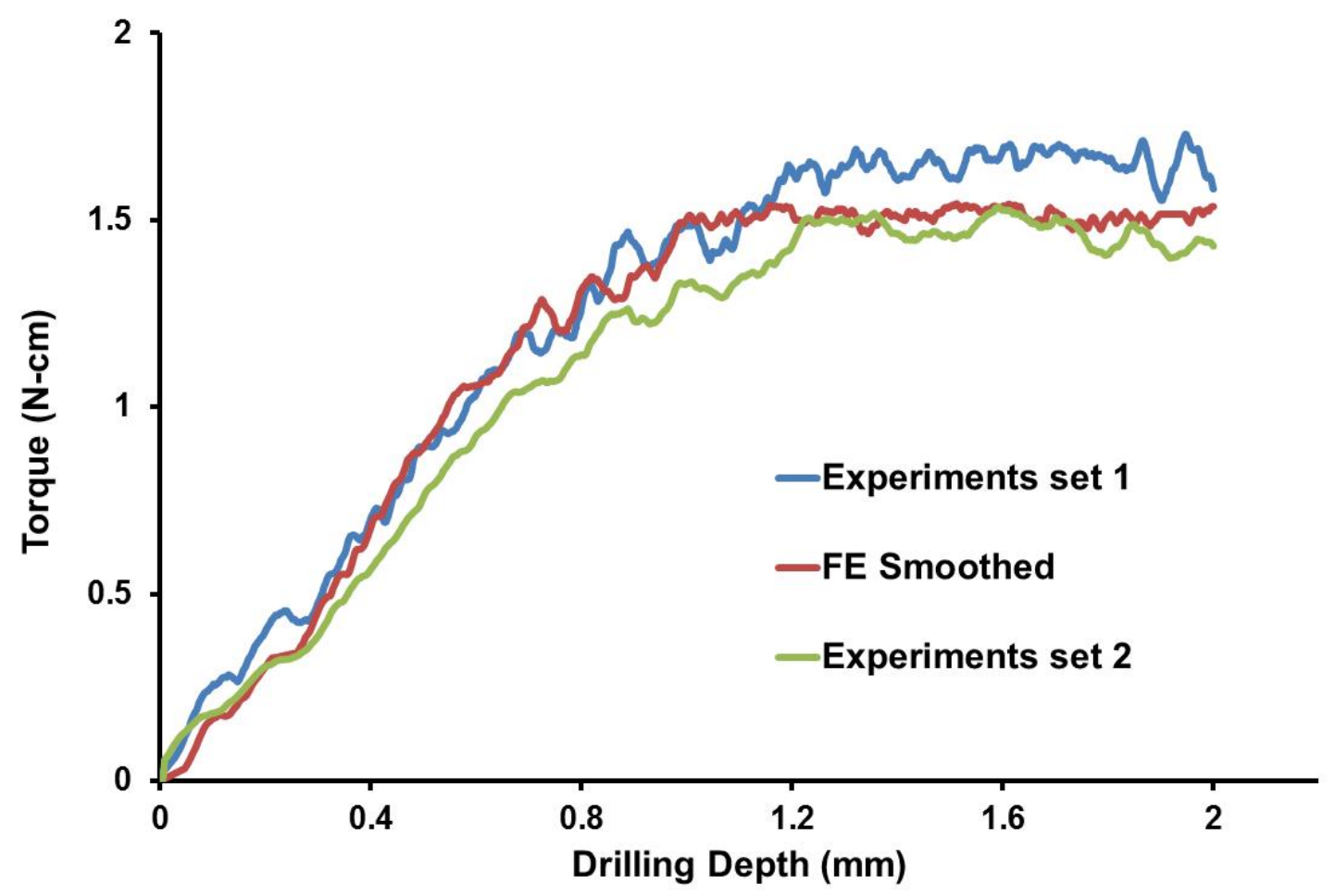

Fig. 6. Experimental validation of FE model at $150 \mathrm{~mm} / \mathrm{min}$ and $800 \mathrm{rpm}$ (a) Thrust force (b) Torque. (The FE data is smoothed using the moving average filter)

\subsection{Prediction of thrust force and torque}

Fig. 7(a) shows the effect of drilling conditions on the average maximum thrust force. Both FE modelling and experimental tests gave similar results. The thrust force was between $28 \mathrm{~N}$ and $70 \mathrm{~N}$ for the range of feed $(\mathrm{mm} / \mathrm{rev})$ modeled. Similar to other studies, the obtained results show that the drilling thrust force increases with increasing feed rate. It can also be observed from Fig. 7a that at a feed of $0.1875 \mathrm{~mm} / \mathrm{rev}$ (obtained from a spindle speed of $800 \mathrm{rpm}$ and a feed rate of $150 \mathrm{~mm} / \mathrm{min}$ ), the average maximum thrust force was the highest, and lowest at a feed of $0.05 \mathrm{~mm} / \mathrm{rev}$ (obtained from a spindle speed of $800 \mathrm{rpm}$ and a feed rate of $40 \mathrm{~mm} / \mathrm{min}$ ). Comparing the levels of thrust force for different feed rates, it was observed that when the feed was increased from $0.05 \mathrm{~mm} / \mathrm{rev}$ to $0.1 \mathrm{~mm} / \mathrm{rev}$ (i.e. from $40 \mathrm{~mm} / \mathrm{min}$ to $80 \mathrm{~mm} / \mathrm{min}$ at $800 \mathrm{rpm}$ spindle speed) the thrust force increased by $60 \%$ and when the feed was increased from $0.1 \mathrm{~mm} / \mathrm{rev}$ to $0.15 \mathrm{~mm} / \mathrm{rev}$ (i.e. from 
$80 \mathrm{~mm} / \mathrm{min}$ to $120 \mathrm{~mm} / \mathrm{min}$ at $800 \mathrm{rpm}$ spindle speed) the thrust force increased by $83 \%$. The effect of drilling speed on torque and force was also examined. The torque decreased significantly as the spindle speed was changed from $800 \mathrm{rpm}$ to $1500 \mathrm{rpm}$ for a feed rate of $150 \mathrm{~mm} / \mathrm{min}$, as shown in Fig. $7 \mathrm{~b}$. This was observed for all the feed rates used in this study. However, the effect of feed rate on the torque is negligible as shown in Fig. 7c. Comparing the level of torque for different feed rates, it was observed that when the feed was increased from $0.05 \mathrm{~mm} / \mathrm{rev}$ to $0.1875 \mathrm{~mm} / \mathrm{rev}$ (i.e. increased from $40 \mathrm{~mm} / \mathrm{min}$ to $150 \mathrm{~mm} / \mathrm{min}$ at a spindle speed of $800 \mathrm{rpm}$ ) the torque increased by only $6 \%$. Also, similar to the effect of spindle speed on the torque, the thrust force decreased as the spindle speed was changed from $800 \mathrm{rpm}$ to $1500 \mathrm{rpm}$ at a feed rate of $120 \mathrm{~mm} / \mathrm{min}$, as shown in Fig. $7 \mathrm{~d}$; such trend was observed for all the feed rates used in this study.

(a)

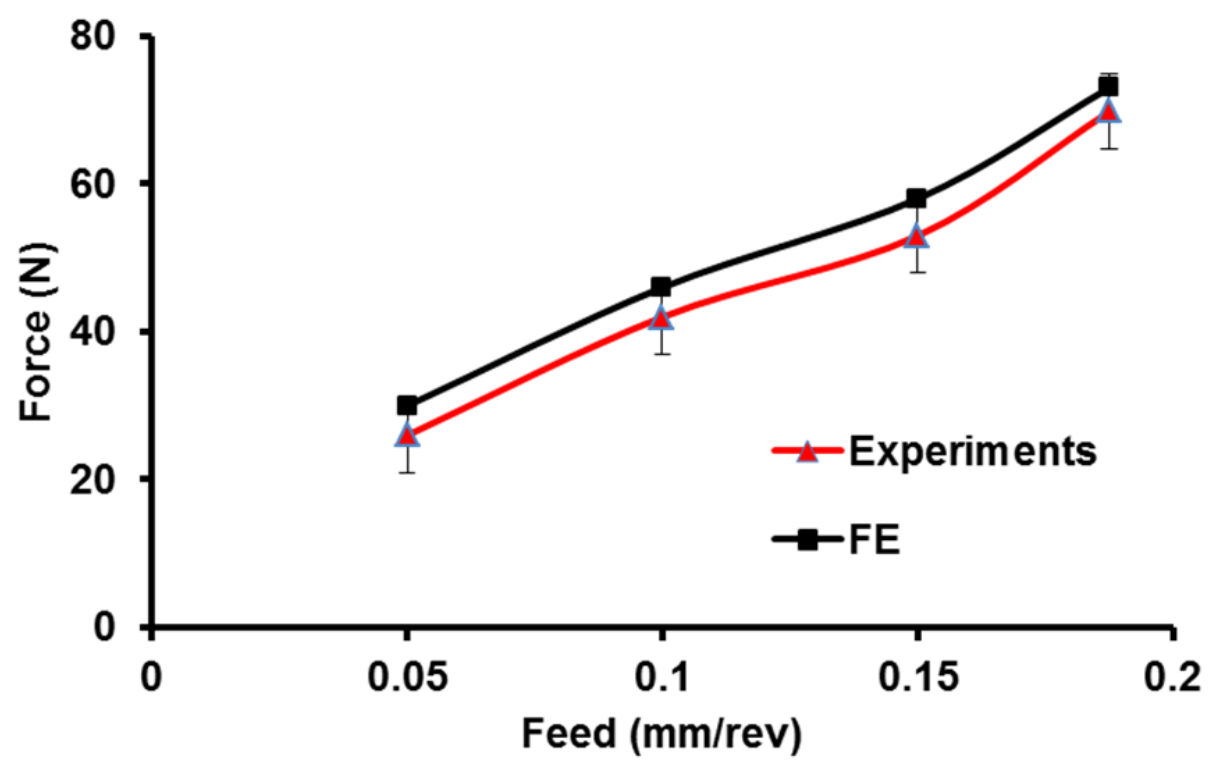


(b)

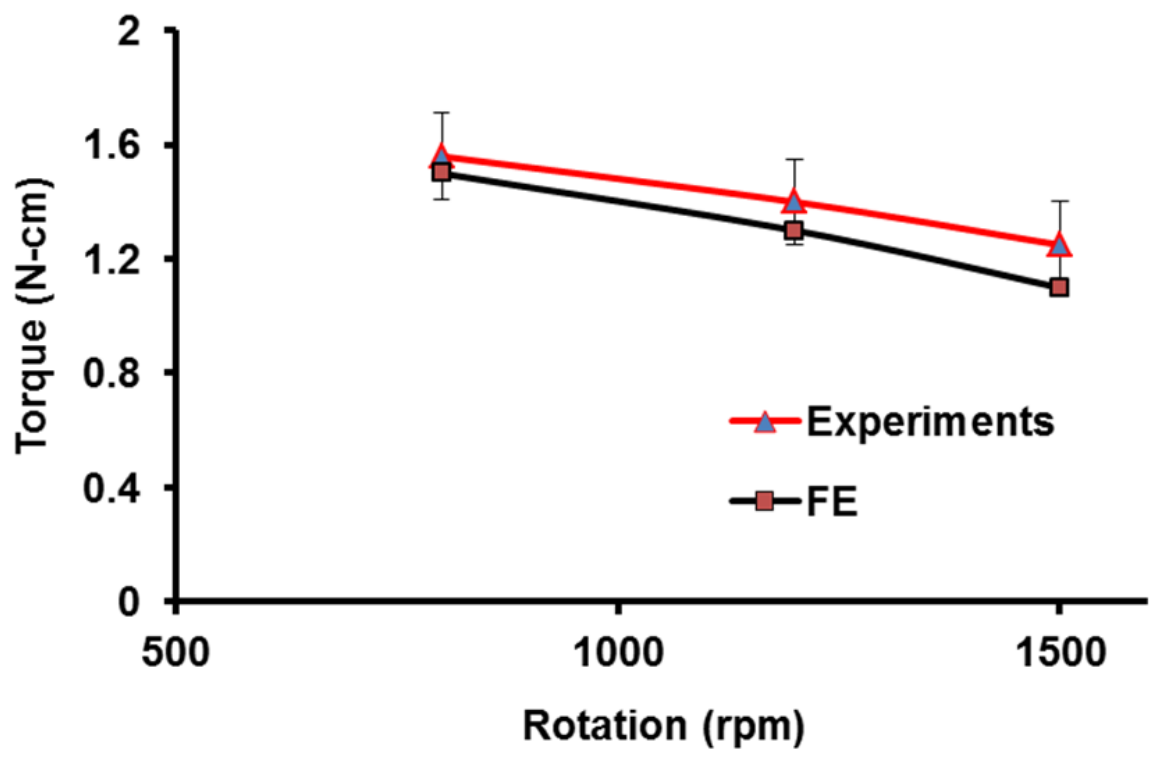

(c)

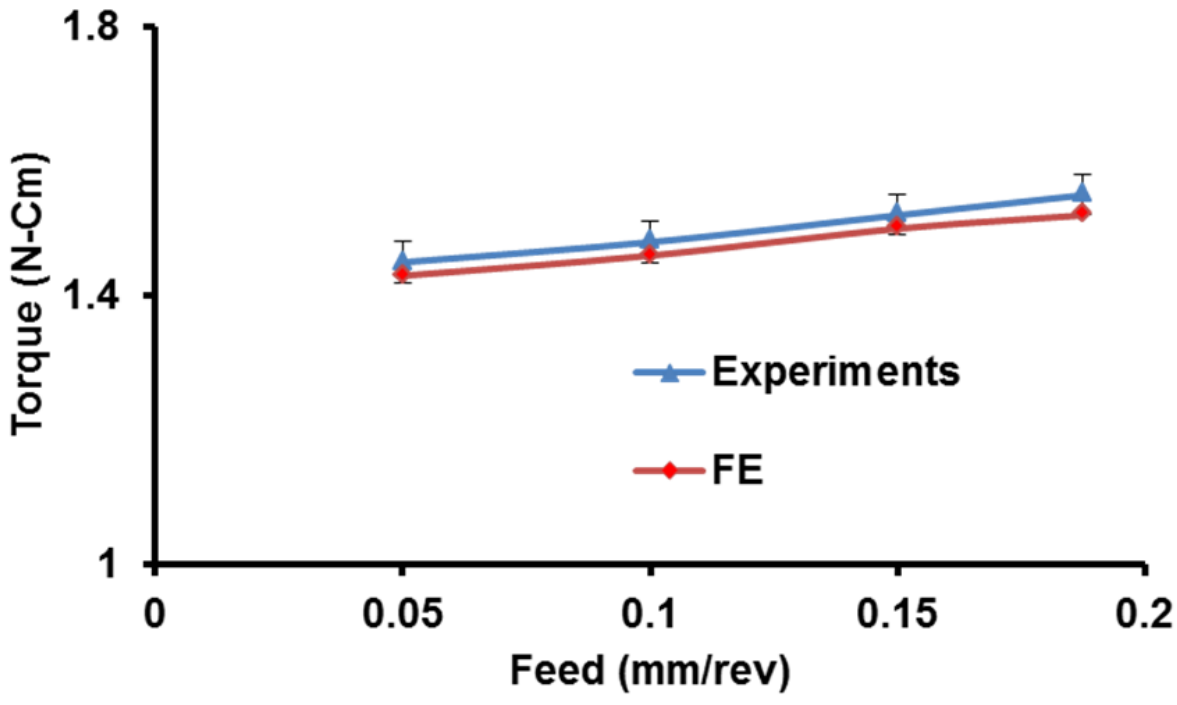


(d)

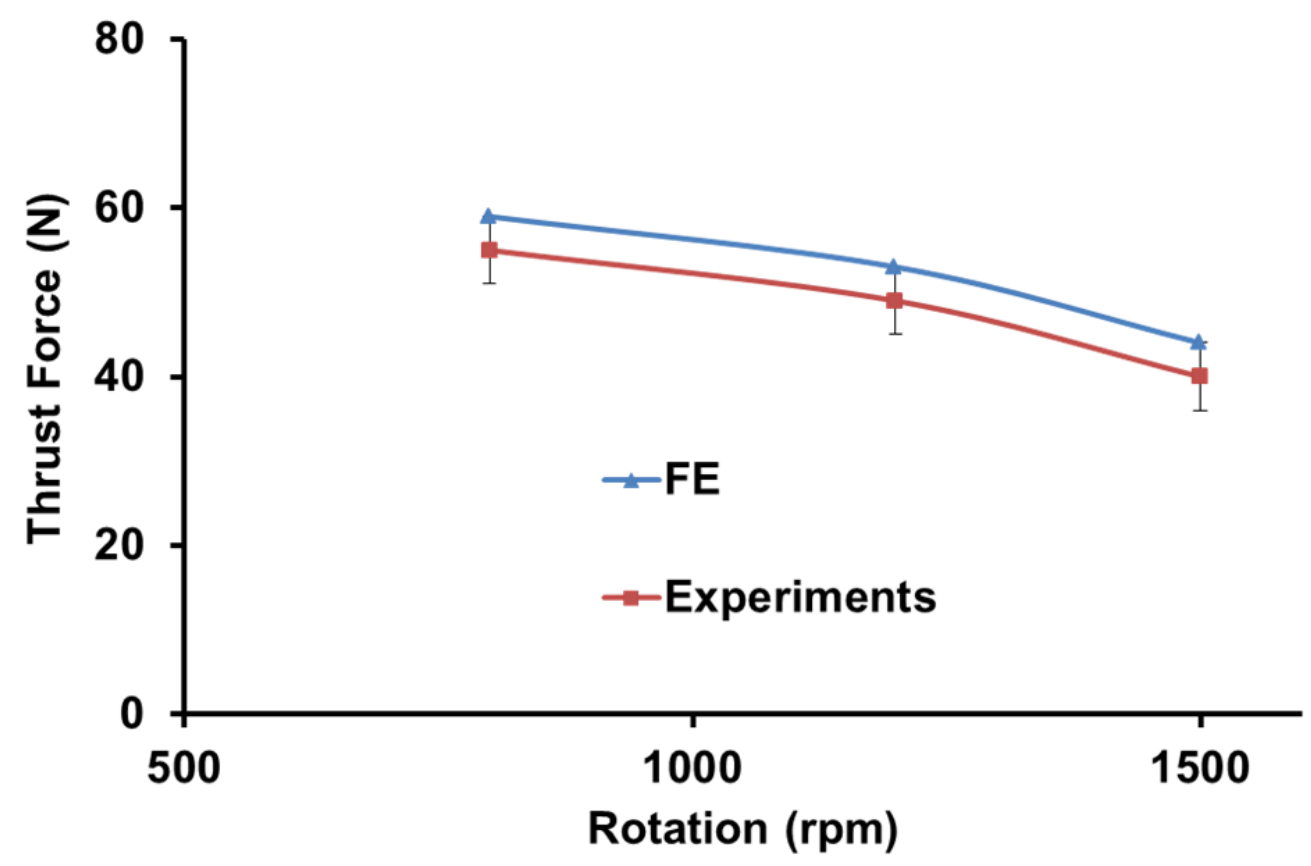

Fig. 7. Comparison of experimental and FE results at different feed rates and spindle speeds (a) Thrust force (with error bar of fixed value \pm 5 ), (b) Torque (with error bar of fixed value \pm 0.15 ), (c) Torque (with error bar of fixed value \pm 0.02 ), (d) Thrust force (with error bar of fixed value \pm 4 )

\subsection{Clinical and biomechanical implications}

As noted earlier, the thrust force data in Fig. 6(a) showed that there was a gradual increase of thrust force during drill-bit entry and gradual drop of thrust during drill-bit exit. This increase and decrease of load is due to the increase and decrease of drill-bit engagement with the bone. The rate of decrease can be used to enhance safety against drill-bit breakthrough. Fig. 6 also shows that there is a fluctuation in force and torque profiles in the experimental results. One reason for this may be the anisotropic nature of bone mechanical properties. Bone porosity, although not directly considered in this study, may be the additional factor that contributes to force and torque fluctuations during drilling. 


\subsection{Comparison to previous studies}

Current findings for maximum thrust force and torque are compared to those reported by others as shown in table 4 (Wiggins et al. 1976, Natali et al. 1996, Ong et al. 1999, 2000, Hillery et al. 1999, Tsai et al. 2007, Alam et al. 2011, Lee et al. 2012, MacAvelia et al. 2012). The presented force and torque results overlap with some reports (Alam et al. 2011, Lee et al. 2012 ) which have values up to $70 \mathrm{~N}$ and $3.8 \mathrm{Ncm}$ respectively. To the authors' knowledge, no 3D numerical study has been reported previously on the prediction of drilling force in cortical bone, only a few studies predict forces in plane cutting of cortical bone using FE models ( Alam et al. 2009, Childs et al. 2011). Consequently, the current study of 3D FE model with material damage law is the first study to predict drilling forces in bovine cortical bone. The difference between the experimental results of various studies arise from the wide variety of test conditions used by researchers regarding drill-bit diameter, drillbit type, rotational speed, feed rate and bone type

\section{Table 4.}

Comparison of presented results with respect to previous studies

\begin{tabular}{|c|c|c|}
\hline STUDY & MATERIAL & RESULT \\
\hline & & Force (N) \\
\hline Present & Bovine femoral shaft & 25 to 75 \\
\hline Wiggin and Malkin & Human femoral shaft & 2 to 300 \\
\hline Natali et al. & Human tibial shaft & 10 to 20 \\
\hline Ong and Bouazza-Marouf & Porcine vertebra & 0.6 to 29.6 \\
\hline Tsai et al. & Human femoral trochanter & 0 to 5 \\
\hline Ong and Bouazza-Marouf & Porcine femoral trochanter & 2 to 24 \\
\hline Ong and Bouazza-Marouf & Porcine femoral head & 4 to 32 \\
\hline Alam et al. & Bovine femoral shaft & 24 to 70 \\
\hline Hillery and Shuaib & Bovine tibial shaft & 24 to 48 \\
\hline Lee et al. & Bovine tibial shaft & 0 to 20 \\
\hline \multirow[t]{2}{*}{ Salahi et al. } & Human femoral shaft & 176 to 198 \\
\hline & & Torque (N.cm) \\
\hline Present & Bovine femoral shaft & 1.2 to 1.6 \\
\hline Wiggin and Malkin & Human femoral shaft & 0.2 to 12 \\
\hline Tsai et al. & Human femoral trochanter & 0 to1 \\
\hline Alam et al. & Bovine femoral shaft & 1 to 2.3 \\
\hline Hillery and Shuaib & Bovine tibial shaft & 1 to 1.45 \\
\hline Allota et al. & Porcine femoral shaft & 5.5 \\
\hline Lee et al. & Bovine tibial shaft & 0 to 3.8 \\
\hline Salahi et al. & Human femoral shaft & 14 to 18 \\
\hline
\end{tabular}




\subsection{Possible limitations}

It should be noted that several factors could improve the accuracy of the simulation results. Amongst these is the use of a more realistic friction model, chip tool interaction, type of chip, inclusion of thermal effects and accounting for drill-bit wear effects. Friction is a contributor to heat generation which may result in bone necrosis. We have not used it in our study because the maximum drilling time was only $3 \mathrm{~s}$ and the bone was fully soaked at room temperature (approx. $25^{\circ} \mathrm{C}$ ). Fonseca et al. (2013) established that there is an increase of $14^{\circ} \mathrm{C}$ in temperature when irrigation is not used, and Eriksson et al. (1984) established that thermal necrosis of cortical bone occurs when the bone is exposed for $1 \mathrm{~min}$ to a threshold temperature of $47^{\circ} \mathrm{C}$. Matthews and Hirsch (1972) investigated human cadaveric femora; they measured the effect of applied force from $19.6 \mathrm{~N}$ to $117.6 \mathrm{~N}$ along with drill-bit speeds varying from $345 \mathrm{rpm}$ to $2900 \mathrm{rpm}$ and concluded that both the temperature above $50^{\circ} \mathrm{C}$ and its time duration decrease as the applied load increases. Also, because of the high elements distortion at the front of the drill-bit, the time step decreases and results in a very high computational time. Therefore, to make the computational time reasonable the distorted elements at the front of the drill-bit were removed, and the chip formation was not modelled; and thus the friction between the chip and the drill-bit was ignored.

The type of element used to discretize the bone may also affect the results. A discrepancy in torque predictions may be due to overly stiff 3D solid elements used with the default reduced-integration scheme available in Abaqus/explicit. Artificially relaxing the stiffness of solid elements may address this issue; this will be a topic of future research and is not addressed in the current study.

Only one drill-bit diameter was used i.e., $\phi 2.5 \mathrm{~mm}$, thereby limiting the present conclusion to this drill-bit size. However, the current diameter is within the range reported in previous literature, and the chosen particular drill-bit is commonly used in clinics. Only three spindle speeds were used, thereby limiting the conclusion to this range. The current speeds are within the range of speeds reported earlier in biomechanics publications. 


\section{Conclusions}

In this paper the effect of different drilling parameters on thrust force and torque in drilling of cortical bone has been investigated both experimentally and numerically. A three dimensional (3D) Lagrangian FE model of drilling on cortical bone was developed using a commercially available FE software ABAQUS/Explicit. The behaviour of cortical bone in elastic regime was defined using the Hill's potential theory for anisotropic materials together with the rate dependent plasticity criterion. An element removal scheme was used based on ductile damage initiation criterion to replicate the hole making process. The following observations are made in this study:

- $\quad$ This is the first study using 3D FE model with a material damage law to predict drilling forces in cortical bone with experimental validation

- $\quad$ The FE model predicted drilling thrust force and torque with reasonable accuracy when compared to experimental results.

- The validated drilling model was used to determine the thrust force, and torque for different drilling conditions. It was observed that the thrust force increased with an increase in feed rate while the torque decreased with an increase in rotational speed. Similarly the thrust force decreased with an increase in rotational speed while the effect of feed rate on the torque was negligible. The thrust force and torque may be reduced using a combination of low feed rate and high rotational speed when drilling in cortical bone within the range of the drilling conditions investigated in this study. However, care must be taken to avoid bone damage (necrosis) if a very low feed rate with high rotational speed (i.e. very low feed per rotation) is chosen without irrigation, especially when drilling in thick bone. Studies carried out by Matthews et al. (1972) and Nam et al. )2006) define the range for safe drilling. 


\section{References}

ALAM, K., MITROFANOV, A. and SILBERSCHMIDT, V.V., 2011. Experimental investigations of forces and torque in conventional and ultrasonically-assisted drilling of cortical bone. Medical Engineering \& Physics, vol. 33, no. 2, pp. 234-239.

ALAM, K., MITROFANOV, A. and SILBERSCHMIDT, V.V., 2009. Finite element analysis of forces of plane cutting of cortical bone. Computational Materials Science, vol. 46 , no. 3 , pp. 738-743.

ALLOTTA, B., BELMONTE, F., BOSIO, L. and DARIO, P., 1996. Study on a mechatronic tool for drilling in the osteosynthesis of long bones: tool/bone interaction, modeling and experiments. Mechatronics, vol. 6, no. 4, pp. 447-459.

Augustin G, Zigman T, Davila S, et al. cortical bone drilling and thermal osteonecrosis. J Clin Biomech. 2012; 27(4):313 e 325.

AUGUSTIN, G., DAVILA, S., MIHOCI, K., UDILJAK, T., VEDRINA, D.S. and ANTABAK, A., 2008. Thermal osteonecrosis and bone drilling parameters revisited. Archives of Orthopaedic and Trauma Surgery, vol. 128, no. 1, pp. 71-77.

BACHUS, K.N., RONDINA, M.T. and HUTCHINSON, D.T., 2000. The effects of drilling force on cortical temperatures and their duration: an in vitro study. Medical Engineering \& Physics, vol. 22, no. 10, pp. 685-691.

BASSI, J.L., PANKAJ, M. and NAVDEEP, S., 2008. A technique for removal of broken cannulated drill bit: Bassi's method. Journal of Orthopaedic Trauma, vol. 22, no. 1 , pp. $56-58$.

BRETT, P., BAKER, D., TAYLOR, R. and GRIFFITHS, M., 2004. Controlling the penetration of flexible bone tissue using the stapedotomy microdrill. Proceedings of the Institution of Mechanical Engineers, Part I: Journal of Systems and Control Engineering, vol. 218, no. 5, pp. 343-351.

CARMOUCHE, J.J., MOLINARI, R.W., GERLINGER, T., DEVINE, J. and PATIENCE, T., 2005. Effects of pilot hole preparation technique on pedicle screw fixation in different regions of the osteoporotic thoracic and lumbar spine. Journal of Neurosurgery: Spine, vol. 3, no. 5, pp. 364-370.

CERETTI, E., Fallbohmer P., Wu W.T., Altan T., "Application of 2D FEM to chip formation in orthogonal cutting", Journal of Material Processing Technology, 59:169180, 1996.

CHEN, W.C., 1997. Applying the finite element method to drill design based on drill deformations. Finite Elements in Analysis and Design, vol. 26, no. 1, pp. 57-81 ISSN 0168-874X. 
CHILDS, T. and AROLA, D., 2011. MACHINING OF CORTICAL BONE:

SIMULATIONS OF CHIP FORMATION MECHANICS USING METAL MACHINING MODELS. Machining Science and Technology, vol. 15, no. 2, pp. 206-230.

COWPER, G. and SYMONDS, P.S., 1957. Strain-Hardening and Strain-Rate Effects in the Impact Loading of Cantilever Beams.

DAVIDSON, S.R.H. and JAMES, D.F., 2003. Drilling in bone: modeling heat generation and temperature distribution. Journal of Biomechanical Engineering, vol. 125, pp. 305.

DELL, R.B., HOLLERAN, S. and RAMAKRISHNAN, R. Sample Size Determination,ILAR Journal 43(4),207-213.

ERIKSSON, A.R., ALBREKTSSON, T. and ALBREKTSSON, B., 1984. Heat caused by drilling cortical bone: temperature measured in vivo in patients and animals. Acta Orthopaedica, vol. 55, no. 6, pp. 629-631.

FARNWORTH, G. and J. BURTON. Optimization of drill geometry for orthopaedic surgeryAnonymous 14th International machine tool design and research conference. Manchester, England, 1974.

FONSECA, E.E.M., Magalhaes, K. ; Fernandes, M.G. ; Sousa, G. ; Barbosa, M.P., 2013. The assessment of the thermal necrosis due a drilling dental process with or without irrigation, IEEE third Portuguese Meeting in Bioengineering (ENBENG): 157-159.

HILL, R., 1990. Constitutive modelling of orthotropic plasticity in sheet metals. Journal of the Mechanics and Physics of Solids, vol. 38, no. 3, pp. 405-417.

HILL, R., 1952. On discontinuous plastic states, with special reference to localized necking in thin sheets. Journal of the Mechanics and Physics of Solids, vol. 1, no. 1, pp. 19-30.

HILLERBORG, A., 1985. The theoretical basis of a method to determine the fracture energyG F of concrete. Materials and Structures, vol. 18, no. 4, pp. 291-296.

HILLERY, M. and SHUAIB, I., 1999. Temperature effects in the drilling of human and bovine bone. Journal of Materials Processing Technology, vol. 92, pp. 302-308.

HOBKIRK, J.A. and RUSINIAK, K., 1977. Investigation of variable factors in drilling bone. Journal of Oral Surgery (American Dental Association : 1965), Dec, vol. 35, no. 12, pp. 968-973 ISSN 0022-3255; 0022-3255.

HSU, Y., 2001. A MODULAR MECHATRONIC SYSTEM FOR AUTOMATIC BONE DRILLING. Biomedical Engineering: Applications, Basis and Communications, vol. 13, no. 04, pp. 168-174 ISSN 1016-2372.

JACOB, C., BERRY, J., POPE, M. and HOAGLUND, F., 1976. A study of the bone machining process-drilling. Journal of Biomechanics, vol. 9, no. 5, pp. 343-349. 
KARALIS, T. and GALANOS, P., 1982. Research on the mechanical impedance of human bone by a drilling test. Journal of Biomechanics, vol. 15, no. 8, pp. 561-581.

KARMANI, S. and LAM, F., 2004. The design and function of surgical drills and Kwires. Current Orthopaedics, vol. 18, no. 6, pp. 484-490.

KASIRI, S., REILLY, G. and TAYLOR, D., 2010. Wedge indentation fracture of cortical bone: experimental data and predictions. Journal of Biomechanical Engineering, vol. 132, no. 8.

LEE, J., GOZEN, B.A. and OZDOGANLAR, O.B., 2012. Modeling and experimentation of bone drilling forces. Journal of Biomechanics, vol. 45, no. 6, pp. 1076-1083.

LEOPOLD, J., Schmidt G., "Challenge and problems with Hybrid Systems for the modeling of machining operations", II CIRP international Workshop on Modeling of Machining Operations, 298-311, 1999.

MACAVELIA, T., SALAHI, M., OLSEN, M., CROOKSHANK, M., SCHEMITSCH, E.H., GHASEMPOOR, A., JANABI-SHARIFI, F. and ZDERO, R., 2012. Biomechanical Measurements of Surgical Drilling Force and Torque in Human Versus Artificial Femurs. Journal of Biomechanical Engineering, vol. 134, no. 12, pp. 124503-124503.

Matthews LS, Hirsch C. Temperatures measured in human cortical bone when drilling. J Bone Joint Surg Am 1972;54A:297-308.

Nam, O.H., Yu, W.J., Choi, M.Y., Kyung, H.M., 2006. Monitoring of bone temperature during osseous preparation for orhodontic micro-screw implants: effect of motor speed and pressure. Key Engineering Materials 321-323, 1044-1047.

NATALI, C., INGLE, P. and DOWELL, J., 1996. Orthopaedic bone drills-can they be improved? Temperature changes near the drilling face. Journal of Bone \& Joint Surgery, British Volume, vol. 78, no. 3, pp. 357-362.

ONG, F. and BOUAZZA-MAROUF, K., 1999. The detection of drill bit break-through for the enhancement of safety in mechatronic assisted orthopaedic drilling. Mechatronics, vol. 9, no. 6, pp. 565-588.

ONG, F. and BOUAZZA-MAROUF, K., 2000. Evaluation of bone strength: correlation between measurements of bone mineral density and drilling force. Proceedings of the Institution of Mechanical Engineers, Part H: Journal of Engineering in Medicine, vol. 214, no. 4, pp. 385-399.

ONG, F.R., 1998. Analysis of bone drilling characteristics for the enhancement of safety and the evaluation of bone strength.

PANTALE, O., Rakotomalala R., Touratier M., Hakem N.,"A three dimensional Numerical Model of orthogonal and oblique metal cutting processes", Engineering Systems Design and Analysis, ASME-PD, 75:199-205, 1996. 
PANTALE, O., 2004. 2D and 3D numerical models of metal cutting with damage effects. Computer Methods in Applied Mechanics and Engineering., vol. 193, no. 39, pp. 4383 ISSN 0045-7825.

PRICE, M., MOLLOY, S., SOLAN, M., SUTTON, A. and RICKETTS, D., 2002. The rate of instrument breakage during orthopaedic procedures. International Orthopaedics, vol. 26, no. 3, pp. 185-187.

REILLY, D.T. and BURSTEIN, A.H., 1975. The elastic and ultimate properties of compact bone tissue. Journal of Biomechanics, vol. 8, no. 6, pp. 393-405.

SAHA, S., PAL, S. and ALBRIGHT, J.A., 1982. Surgical drilling: design and performance of an improved drill. Journal of Biomechanical Engineering, Aug, vol. 104, no. 3, pp. 245-252 ISSN 0148-0731; 0148-0731.

STRENKOWSKI, J.S., HSIEH, C.C. and SHIH, A.J., 2004. An analytical finite element technique for predicting thrust force and torque in drilling. International Journal of Machine Tools and Manufacture, 10, vol. 44, no. 12-13, pp. 1413-1421 ISSN 0890-6955. DOI DOI: 10.1016/j.ijmachtools.2004.01.005.

THOMPSON, H.C., 1958. Effect of drilling into bone. Journal of Oral Surgery, Jan, vol. 16, no. 1, pp. 22-30 ISSN 0146-1575; 0146-1575.

TSAI, M., HSIEH, M. and TSAI, C., 2007. Bone drilling haptic interaction for orthopedic surgical simulator. Computers in Biology and Medicine, vol. 37, no. 12, pp. $1709-1718$.

TU, Y., H. TSAI, L. CHEN, C. HUANG, Y. CHEN and L. LIN. Finite element simulation of drill bit and bone thermal contact during drillingAnonymous Bioinformatics and Biomedical Engineering, 2008. ICBBE 2008. The 2nd International Conference on, 2008.

VAN BRUSSEL, K., SLOTEN, J.V., VAN AUDEKERCKE, R. and FABRY, G., 1996. Internal fixation of the spine in traumatic and scoliotic cases. The potential of pedicle screws. Technology and Health Care, vol. 4, no. 4, pp. 365-384.

VASHISHTH, D., 2004. Rising crack-growth-resistance behavior in cortical bone:: implications for toughness measurements. Journal of Biomechanics, vol. 37, no. 6 , pp. 943-946.

WIGGINS, K. and MALKIN, S., 1976. Drilling of bone. Journal of Biomechanics, vol. 9, no. 9, pp. 553-559. 